\title{
Note \\ Identification and Heterologous Expression of the Topopyrone Nonaketide Synthase Gene from Phoma sp.
}

\author{
Nobuyuki Kashiwa, ${ }^{a}$ Yutaka Ebizuka, ${ }^{a}$ and Isao Fujii ${ }^{*}, b$ \\ ${ }^{a}$ Graduate School of Pharmaceutical Sciences, The University of Tokyo; 7-3-1 Hongo, Bunkyo-ku, \\ Tokyo 113-0033, Japan: and ${ }^{b}$ School of Pharmacy, Iwate Medical University; \\ 2-1-1 Nishitokuta, Yahaba, Iwate 028-3694, Japan. \\ Received February 22, 2016; accepted March 9, 2016
}

\begin{abstract}
Non-reducing iterative type I polyketide synthase genes, pnk1 and $p n k 2$, were cloned from the fungus Phoma sp. BAUA2861, which produces the topoisomerase I inhibitors, topopyrones A to D. Heterologous expression of these polyketide synthase genes under the $\alpha$-amylase promoter in Aspergillus oryzae was carried out to identify their functions. The pnk 2 transformant produced topopyrones $\mathrm{C}$, $\mathrm{D}$, and haematommone. Therefore, the pnk2 gene was found to encode for the topopyrone nonaketide synthase.
\end{abstract}

Key words topopyrone; polyketide synthase; gene cloning; heterologous expression

DNA topoisomerases are nuclear enzymes that participate in the processing of DNA and are essential for chromosomal segregation and relaxation of DNA during replication and transcription. ${ }^{1)}$ They are classified as either type I or type II. The former is a ubiquitous nuclear enzyme catalyzing the relaxation of superhelical DNA by inducing a transient single strand nick in the duplex, while the latter mediates the ATP-dependent induction of coordinated nicks in both strands of the DNA duplex resulting in transient duplex breakage. ${ }^{2)}$ Etoposide and anthracyclines are used clinically for antitumor agents as human topoisomerase II inhibitors. ${ }^{3-5)}$ In contrast, camptothecin derivatives are only used clinically as human topoisomerase I inhibitors. ${ }^{6)}$ Recently, several promising new topoisomerase I inhibitors have been identified including topopyrones, which are planar anthraquinones having a fused 1,4-pyrone ring in either a linear or angular type. ${ }^{78}$ Topopyrones A to D, were first isolated from the culture broths of two fungi, Phoma sp. BAUA2861 and Penicillium sp. BAUA4206, as human topoisomerase I inhibitors. Topopyrones A and B possess a chloro substituent, while topopyrones $\mathrm{C}$ and $\mathrm{D}$ are unsubstituted (Fig. 1).

Topopyrones inhibited the growth of yeast expressing

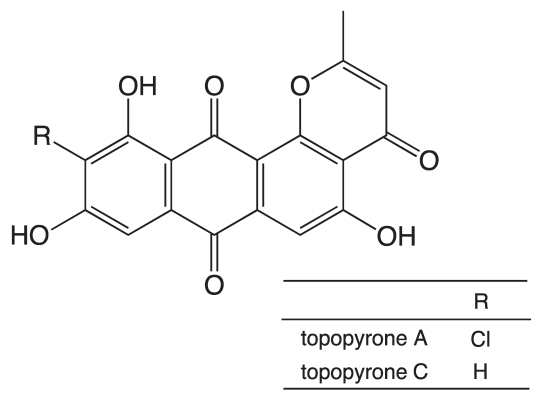

human topoisomerase I and no cytotoxicity was observed when the yeast was grown under conditions that precluded topoisomerase I expression. They also inhibited DNA relaxation mediated by topoisomerase I, but not by topoisomerase II. ${ }^{7)}$ Recent studies reported that topopyrones are also strong topoisomerase II poisons in addition to stabilizing the topoisomerase I-DNA covalent binary complex. ${ }^{9)}$ Thus, topopyrones represent unique molecules capable of interacting effectively with two types of DNA topoisomerases.

After the isolation and structural determination of topopyrones, some synthetic research has been published on this interesting group of compounds. ${ }^{10)}$ However, no biosynthetic studies have been carried out including cloning of genes responsible for their biosynthesis. Thus, we initiated a molecular genetic approach to clone the biosynthetic genes for topopyrones from Phoma sp. BAUA2861. From the planar anthraquinone structure fused with the pyrone ring and the consideration of the biosynthesis of related naphthopyrones and anthraquinone, the non-reducing iterative type I polyketide synthase (NR-PKS) was thought to be responsible for the initial steps of topopyrone biosynthesis (Fig. 2).

Following our gene cloning and functional expression

Topopyrones from Phoma sp. BAUA2861

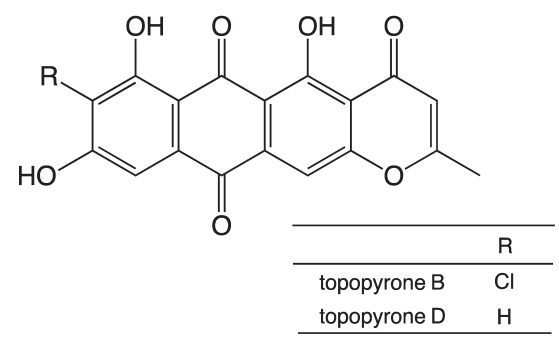

* To whom correspondence should be addressed. e-mail: ifujii@iwate-med.ac.jp 


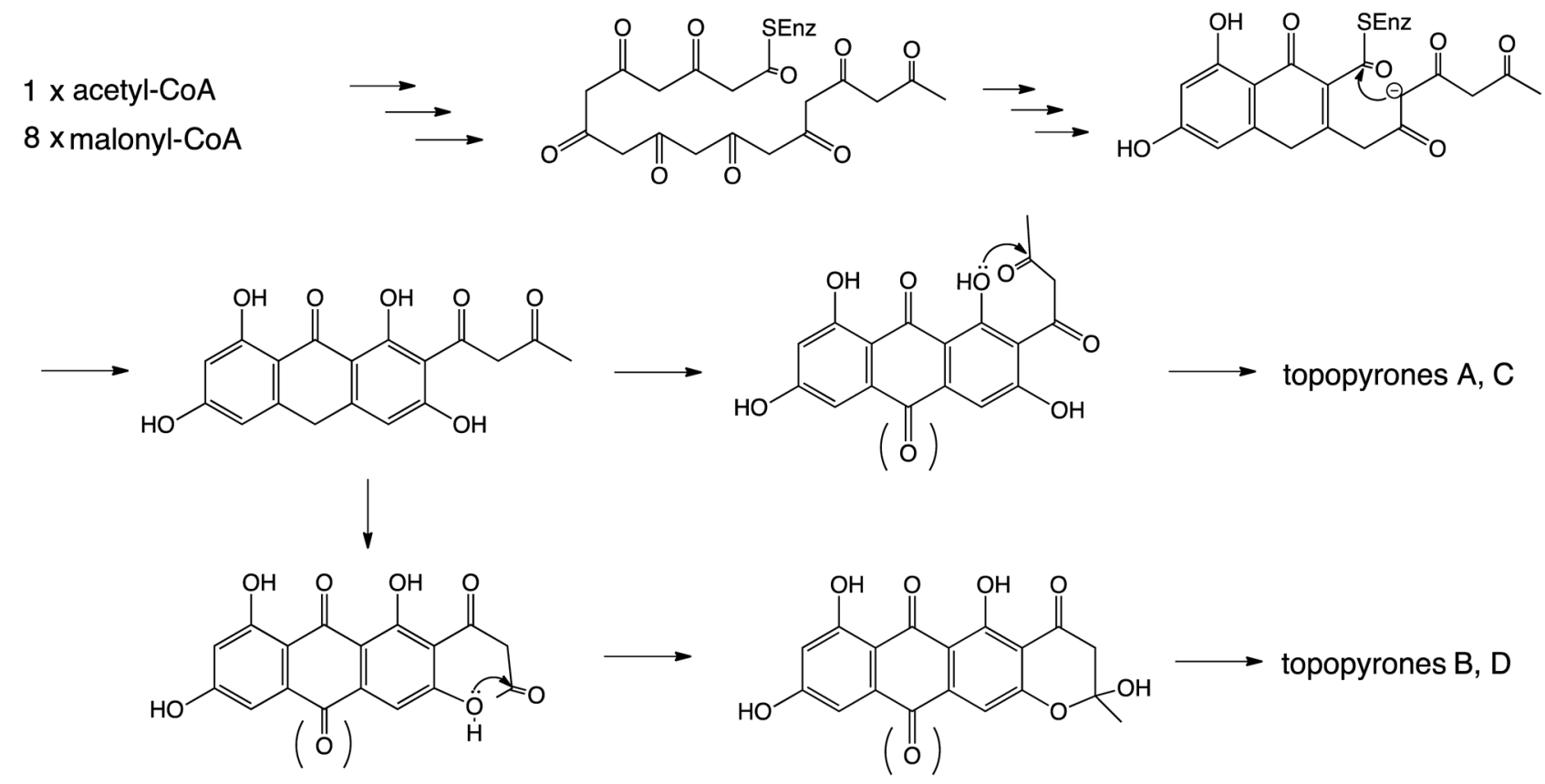

Fig. 2. Proposed Biosynthesis of Topopyrones

PNK1 (2153 aa)

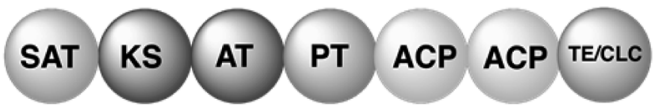

PNK2 (2038 aa)

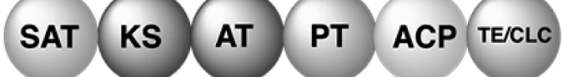

SAT: starter acyltransferase, KS: ketosynthase, AT: acyltransferase, PT: product template domain, DH: dehydratase,

MeT: methyltransferase, ER: enoyl reductase, KR: keto reductase, ACP: acyl carrier protein, TE/CLC: thioesterase/Claisen cyclase

Fig. 3. Architecture of PNK1 and PNK2

experiments on fungal NR-PKSs such as WA, ${ }^{11)}$ Alb1, ${ }^{12)}$ PKS1, ${ }^{13)}$ and AcTHN synthase, ${ }^{14)}$ we designed primers for NR-PKS gene amplification by targeting the most highly conserved region of NR-PKSs, the $\beta$-ketoacyl synthase (KS) to acyltransferase (AT) region. A pair of degenerated primers, KSD-II-F: 5'-GAR ATG CAY GCH ACH GGK AC-3' based on the EMHATG T amino acid sequence and KSD-II-R: 5'-TTY ACN GGN CAR GGN GCN CAR TA-3' based on the YQAGQGTF amino acid sequence were designed. PCR amplification with the Phoma sp. BAUA2861 genomic DNA as a template gave a main fragment of $c a .750 \mathrm{bp}$. After T-vector cloning of the amplified fragments, four independent fragments labeled A to D were obtained from 36 clones. The most abundant fragment, A (22 clones out of 36 clones), showed high homology with a tetrahydroxynaphthalene synthase such as $C$. lagenarium $\mathrm{PKS}^{13)}$ and the least abundant fragment, $\mathrm{D}$ (two clones out of 36 clones) showed similarity with highly reducing-type PKSs such as LovB of lovastatin biosynthesis. ${ }^{15}$ ) Because the two other fragments, B and C, showed similarity with NR-PKSs such as WA ${ }^{11)}$ and PKSL1, ${ }^{16)}$ these fragments were chosen for further analysis.

To determine the full-length PKS sequences containing these fragments, we used the genome walking method developed by Siebert et al. ${ }^{17)}$ Genomic DNA was digested with a blunting restriction enzyme and adaptors were ligated to the end of the fragments. Several types of genomic DNA library pools digested with blunting restriction enzymes were constructed. Then, nested PCRs using internal primers and adaptor primers were performed on the adaptor-ligated restricted genomic DNA pool as a template. The PCR products were sequenced directly or after T-vector subcloning. Thus, the full-length sequences of two Phoma NR-PKS genes were determined and these PKS genes were named pnk1 and pnk2 from fragments $\mathrm{B}$ and $\mathrm{C}$, respectively.

Pnkl is 6555 bp long with two putative introns encoding a 2153 amino acid protein consisting of starter acyltransferase (SAT), ketosynthase (KS), acyltransferase (AT), tandem acyl carrier proteins (ACPs), and thioesterase/Claisen cyclase (TE/ CLC $)^{18)}$ domains. Pnk2 is 6334 bp long with four putative introns encoding a 2038 amino acid protein consisting of SAT, KS, AT, a single ACP, and TE/CLC. Both PKSs have an architecture common to fungal NR-PKSs (Fig. 3).

To determine the PKS functions of PNK1 and PNK2, we attempted to express these NR-PKSs in the heterologous host A. oryzae as previously reported. ${ }^{11)}$ The PKS genes were PCR amplified from the Phoma genomic DNA with specific forward and reverse primers with att $\mathrm{B}$ sites at their 5 '-end for Gateway cloning. The PCR amplification was carried out using the Phusion HF DNA polymerase (New England Biolabs). The amplified product was cloned into the expression vector pTAex3R derived from pTAex $3^{19)}$ containing the $a m y B$ promoter and terminator for inducible gene expression by the Gateway cloning method. The constructed expression plasmids pTA-PNK1 and pTA-PNK2 were transformed into $A$. oryzae $\mathrm{M}-2-3^{20)}$ 


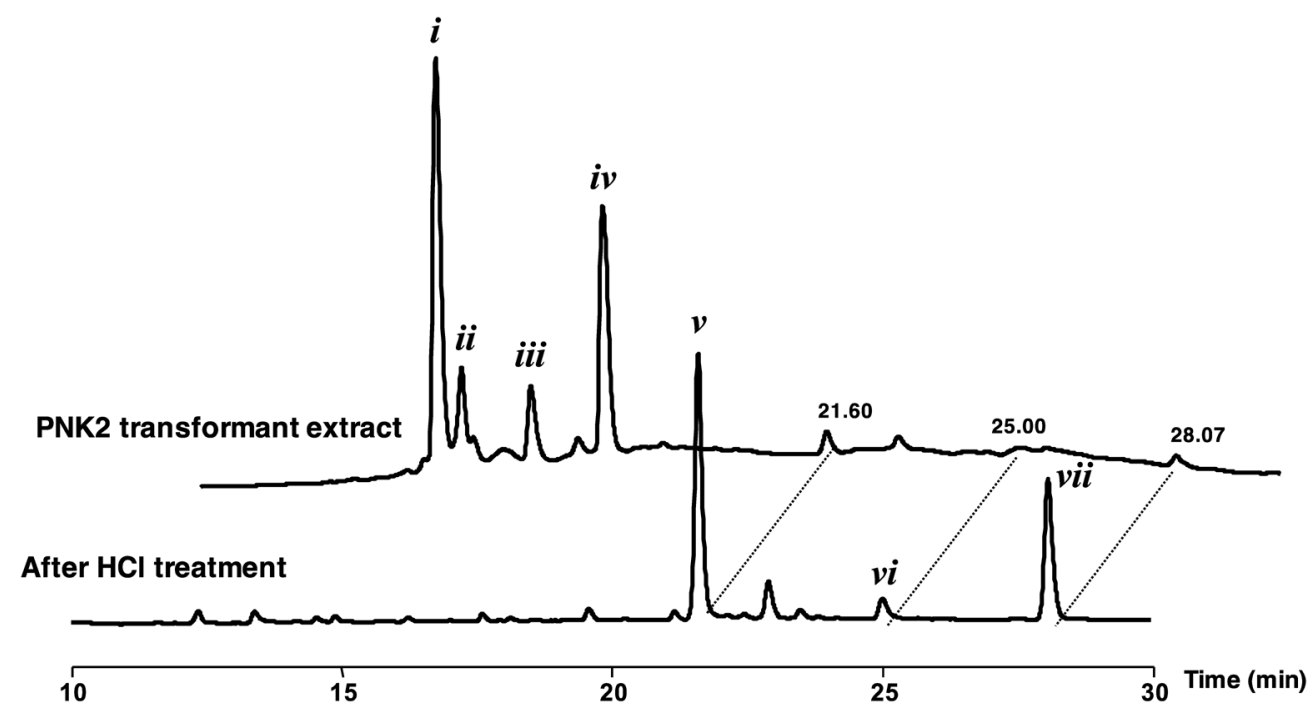

Fig. 4. HPLC Analysis of the PNK2 Transformant Extract

Column: Tosoh ODS- $80 \mathrm{~T}_{\mathrm{M}}(4.6 \times 150 \mathrm{~mm})$; eluent: $10-70 \%$ aq. $\mathrm{CH}_{3} \mathrm{CN} / 25 \mathrm{~min}$; flow rate: $1 \mathrm{~mL} / \mathrm{min}$; temp.: $40^{\circ} \mathrm{C}$; detection: $450 \mathrm{~nm}$.<smiles>CC(=O)Oc1cc(OC(C)=O)c2c(c1)C(=O)c1cc3oc(C)cc(=O)c3c(OC(C)=O)c1C2=O</smiles>

topopyrone $\mathrm{D}$ triacetate (1)<smiles>CC(=O)Oc1cc(OC(C)=O)c2c(c1)C(=O)c1cc(OC(C)=O)c3c(=O)cc(C)oc3c1C2=O</smiles>

topopyrone $\mathrm{C}$ triacetate (2)<smiles>CC(=O)Oc1cc(OC(C)=O)c2c(c1)C(=O)c1cc(OC(C)=O)c(C(C)=O)c(O)c1C2=O</smiles>

haematommone triacetate (3)

Fig. 5. Structures of the Acetylated PNK2 Products

by a protoplast-polyethylene glycol (PEG) method. ${ }^{21}$ The $A$. oryzae M-2-3 transformant with pTAex3 served as a control. Transformants selected on minimal medium were first cultured in dextrin-polypeptone-yeast extract (DPY) medium ${ }^{21)}$ and then transferred to the Czapek-Dox media containing starch to induce the expression of the PKS gene under the $\alpha$-amylase promoter. After culturing in the induction media for $3 \mathrm{~d}$, an ethyl acetate extract of the culture media under acidic conditions gave no product in either PNK1 transformants or PNK2 transformants. In contrast, the PNK2 induction culture mycelia showed reddish pigmentation. Thus, the mycelia of PNK2 transformants were extracted with methanol at room temperature overnight and analyzed by HPLC. While extracts of the control and the PNK1 transformants did not give any specific peaks when analyzed by HPLC, the mycelial extract of the PNK2 transformant gave four main peaks $\boldsymbol{i}$ to $\boldsymbol{i} \boldsymbol{v}$ and minor peaks $v$ to $\boldsymbol{v i}$, which were considered to be specific for PNK2 expression. The components of the main peaks $\boldsymbol{i}$ to $\boldsymbol{i} v$ were found to be relatively unstable even at room temperature and converted to more hydrophobic compounds later found to be identical with the minor peaks $v$ to vii. The components of the main peaks $\boldsymbol{i}$ to $\boldsymbol{i} \boldsymbol{v}$ were assumed to be $O$-sulfated derivatives of peaks $\boldsymbol{v}$ to $\boldsymbol{v i}$ by LC-electrospray ionization (ESI)-MS analysis as $O$-sulfation was previously observed in $A$. oryzae heterologous expression of NR-PKS ${ }^{22)}$ (Fig. 4).

This component conversion was found to be promoted by acidic conditions. Thus, the mycelia of PNK2 transfor- mant from a 1-L induction culture were extracted with $2 \mathrm{~L}$ methanol acidified with $\mathrm{HCl}$ by stirring at room temperature overnight. After extraction with ethyl acetate, the products were redissolved in $1 \mathrm{~m} \mathrm{NaOH}$ and then extracted again with ethyl acetate after acidification. Because the evaporated residue was difficult to dissolve in organic solvents, acetylation was carried out with acetic anhydride/pyridine. After silica gel column chromatography, three compounds were isolated. Compound 1 was identified to be topopyrone $\mathrm{D}$ triacetate $^{8)}$ by physicochemical analysis. Compounds $\mathbf{2}$ and $\mathbf{3}$ were identified to be topopyrone $\mathrm{C}$ triacetate $^{8)}$ and haematommone triacetate, respectively (Fig. 5). Isolation of haematommone from the lichen Haematomma puniceum was reported previously. ${ }^{23)}$

Therefore, these results indicated that $p n k 2^{24)}$ encodes a PKS involved in topopyrone biosynthesis because topopyrones were the major products of the PNK2 transformant. PNK2 is considered to be a nonaketide synthase catalyzing the condensation of acetyl-CoA and eight malonyl-CoAs to form a nonaketide intermediate. This intermediate is then cyclized to form a bicyclic intermediate by aldol condensation and the third-ring cyclization is catalyzed by CLC to release the anthrone product. It is known that anthrone can be enzymatically or non-enzymatically oxidized to anthraquinone in fungi. ${ }^{25)}$ Hemiketal formation of a diketide side chain with a phenolic hydroxy group forms either an angular- or lineartype pyrone structure and its dehydration results in the formation of topopyrones. Once the starter acetyl group is replaced 


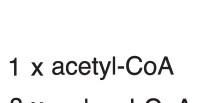

$8 \times$ malonyl-CoA
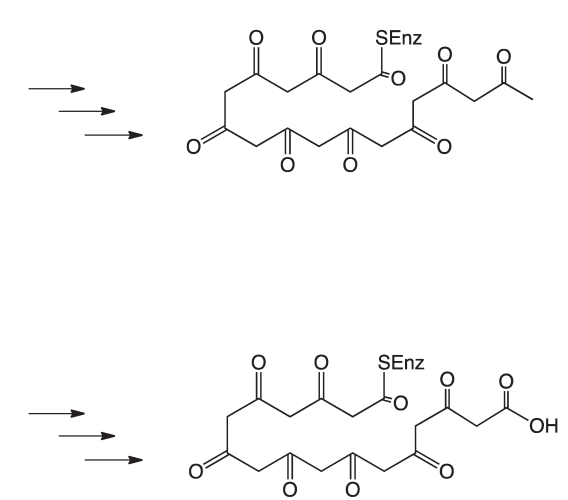
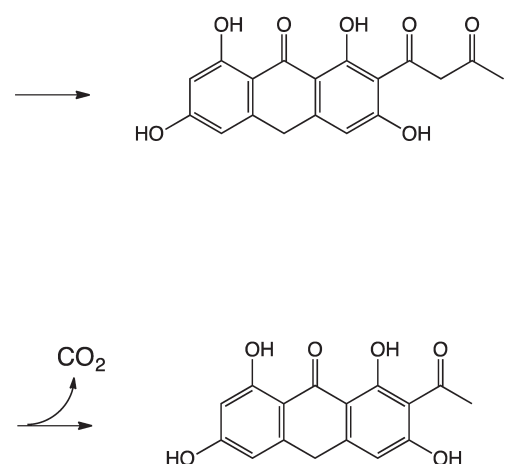

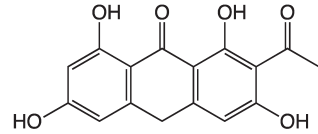

$\longrightarrow$ haematommone

Fig. 6. Proposed PNK2 Reaction

with a malonyl group, decarboxylation of the starter malonate can occur. The following PKS catalyzed reaction would then form an octaketide anthrone and its subsequent oxidation would give the octaketide anthraquinone, haematommone. A similar decarboxylation phenomenon for a PKS catalyzed reaction was observed in the expression of $C$. lagenarium PKS1 to form the pentaketide, $\alpha$-acetyl orsellinic acid ${ }^{26)}$ (Fig. 6).

In summary, we succeeded in the cloning and heterologous expression of the topopyrone PKS gene, pnk2. It was reported that the chloro substituted topopyrones A and B are more potent than the unsubstituted topopyrones $\mathrm{C}$ and $\mathrm{D}$ in terms of their topoisomerase I inhibition. ${ }^{7)}$ The halogenase gene responsible for the derivatization of topopyrones A and D may be in the topopyrone biosynthetic gene cluster in producing fungi and will be a key target to identify. Co-expression of pnk2 and the halogenase gene in A. oryzae should provide an efficient biological production system of these important anticancer drug candidates.

\section{Experimental}

General Analytical HPLC was carried out on Tosoh HPLC system with DP 8020 pump and PD8020 photodiode array detector using a Tosoh ODS-80T $\mathrm{T}_{\mathrm{M}}$ column $(4.6 \times 150 \mathrm{~mm})$. LC-ESI-MS data were obtained on an Agilent 1100 HPLC-microTOF mass spectrometer (BRUKER DALTONICS). NMR spectra were obtained on an JEOL ECA500 $500 \mathrm{MHz}$ spectrometer.

Fungal Strains and Culture The fungus Phoma sp. BAUA2861 was provided by the Institute of Biotechnology Applied to Soil Eumycetes and cultured as previously reported. ${ }^{7)}$ Aspergillus oryzae $\mathrm{M}-2-3^{20)}$ was used as the host fungus to express NR-PKS genes. Czapek-Dox medium containing starch was used as induction culture medium of $A$. oryzae transformants.

DNA Manipulation Genomic DNA of Phoma sp. BAUA2861 was prepared according to the reported method ${ }^{27)}$ and was used as the template to amplify NR-PKS genes. pTAex3R, a Gateway version of pTAex $3,{ }^{19)}$ was used to construct the expression plasmids pTA-PNK1 and pTA-PNK2. These plasmids were transformed into Aspergillus oryzae M-2-3 by protoplast-PEG method. ${ }^{21)}$ Nucleotide sequences were determined using ABI PRISM 3100 Genetic Analyzer. The PCR-based gene walking method ${ }^{17)}$ was applied to extend the $5^{\prime}$ and $3^{\prime}$ terminal sequences of the PKS gene fragments to determine the full-length PKS genes.

Isolation of PNK2 Products The A. oryzae pTA-PNK2 transformant was cultured in Czapek-Dox induction medium containing starch for $3 \mathrm{~d}$ at $30^{\circ} \mathrm{C}$. Then its mycelia were extracted with methanol containing $1 \mathrm{M} \mathrm{HCl}$. The methanol extract was concentrated and re-extracted with ethyl acetate. The evaporated residues redissolved in $1 \mathrm{M} \mathrm{NaOH}$ were then extracted with ethyl acetate after acidification. Thus obtained crude PNK2 products were acetylated by acetic anhydride/ pyridine and separated by silica gel column chromatography (Wakogel C-200) with $n$-hexane/ethyl acetate solvent system.

Topopyrone D Triacetate (1)

${ }^{1} \mathrm{H}-\mathrm{NMR}\left(\mathrm{CDCl}_{3}\right) \delta: 2.34(3 \mathrm{H}, \mathrm{s}), 2.40(3 \mathrm{H}, \mathrm{s}), 2.45(3 \mathrm{H}, \mathrm{s})$, $2.52(3 \mathrm{H}, \mathrm{s}), 6.13(1 \mathrm{H}, \mathrm{s}), 7.29(1 \mathrm{H}, \mathrm{d}, J=2.3 \mathrm{~Hz}), 7.97(1 \mathrm{H}, \mathrm{d}$, $J=2.3 \mathrm{~Hz}), 8.20(1 \mathrm{H}, \mathrm{s}) .{ }^{13} \mathrm{C}-\mathrm{NMR}\left(\mathrm{CDCl}_{3}\right) \delta: 20.15$ (d), 20.95 (q), 21.03 (q), 21.10 (q), 112.83 (d), 115.34 (d), 118.44 (d), 121.19 (s), 122.23 (s), 124.07 (s), 124.07 (d), 135.27 (s), 136.24 (s), 151.62 (s), 154.71 (s), 154.71 (s), 159.46 (s), 165.71 (s), 169.06 (s), 169.06 (s), 167.92 (s), 175.62 (s), 178.26 (s), 180.02 (s).

Topopyrone C Triacetate (2)

${ }^{1} \mathrm{H}-\mathrm{NMR}\left(\mathrm{CDCl}_{3}\right) \delta: 2.37(3 \mathrm{H}, \mathrm{s}), 2.46(3 \mathrm{H}, \mathrm{s}), 2.50(3 \mathrm{H}$, s), $2.50(3 \mathrm{H}, \mathrm{s}), 6.20(1 \mathrm{H}, \mathrm{s}), 7.31(1 \mathrm{H}, \mathrm{d}, J=2.9 \mathrm{~Hz}), 7.84(1 \mathrm{H}$, s), $7.96(1 \mathrm{H}, \mathrm{d}, J=2.9 \mathrm{~Hz}) \cdot{ }^{13} \mathrm{C}-\mathrm{NMR}\left(\mathrm{CDCl}_{3}\right) \delta: 20.72(\mathrm{~d})$, 21.07 (q), 21.11 (q), 21.13 (q), 112.52 (d), 116.95 (d), 118.37 (d), 121.10 (s), 121.17 (s), 123.82 (s), 123.96 (d), 134.68 (s), 136.85 (s), 151.34 (s), 153.70 (s), 154.68 (s), 156.58 (s), 166.72 (s), 167.96 (s), 168.96 (s), 169.18 (s), 175.71 (s), 178.30 (s).

Haematommone Triacetate (3)

${ }^{1} \mathrm{H}-\mathrm{NMR}\left(\mathrm{CDCl}_{3}\right) \delta: 2.37(1 \mathrm{H}, \mathrm{s}), 2.44(1 \mathrm{H}, \mathrm{s}), 2.55(1 \mathrm{H}, \mathrm{s})$, $2.73(1 \mathrm{H}, \mathrm{s}), 7.26(1 \mathrm{H}, \mathrm{d}, J=2.3 \mathrm{~Hz}), 7.75(1 \mathrm{H}, \mathrm{s}), 7.94(1 \mathrm{H}, \mathrm{d}$, $J=2.3 \mathrm{~Hz}),{ }^{13} \mathrm{C}-\mathrm{NMR}\left(\mathrm{CDCl}_{3}\right) \delta: 21.04(\mathrm{q}), 21.08(\mathrm{q}), 21.83(\mathrm{q})$, 32.91 (q), 115.51 (d), 118.39 (d), 119.02 (s), 119.02 (s), 123.54 (s), 123.89 (d), 135.33 (s), 135.95 (s), 151.58 (s), 153.61 (s), 154.66 (s), 156.52 (s), 167.03 (s), 168.30 (s), 168.56 (s), 178.89 (s), 180.42 (s), 203.95 (s).

Acknowledgments This work was supported in part by a Grant-in-Aid for Scientific Research (B) (No. 19310139) to I.F. from the Japan Society for the Promotion of Science and by a Grant-in-Aid for Scientific Research on the Priority Area "Applied Genomics" to I.F. from the Ministry of Education, Culture, Sports, Science and Technology of Japan. We thank the Institute of Biotechnology Applied to Soil Eumycetes for providing the fungal strain.

Conflict of Interest The authors declare no conflict of interest. 


\section{References and Notes}

1) Wang J. C., Nat. Rev. Mol. Cell Biol., 3, 430-440 (2002).

2) Champoux J. J., Annu. Rev. Biochem., 70, 369-413 (2001).

3) Chen A. Y., Liu L. F., Annu. Rev. Pharmacol. Toxicol., 34, 191-218 (1994).

4) Wilstermann A. M., Bender R. P., Godfrey M., Choi S., Anklin C., Berkowitz D. B., Osheroff N., Graves D. E., Biochemistry, 46, 8217-8225 (2007).

5) Pang B., de Jong J., Qiao X., Wessels L. F. A., Neefjes J., Nat. Chem. Biol., 11, 472-480 (2015).

6) Potmesil M., Cancer Res., 54, 1431-1439 (1994).

7) Kanai Y., Ishiyama D., Senda H., Iwatani W., Takahashi H., Konno H., Tokumasu S., Kanazawa S., J. Antibiot., 53, 863-872 (2000).

8) Ishiyama D., Kanai Y., Senda H., Iwatani W., Takahashi H., Konno H., Kanazawa S., J. Antibiot., 53, 873-878 (2000).

9) Khan Q. A., Elban M. A., Hecht S. M., J. Am. Chem. Soc., 130, 12888-12889 (2008).

10) Zaleski P. A., Maini R., Leiris S. J., Elban M. A., Hecht S. M., J. Nat. Prod., 75, 577-585 (2012).

11) Watanabe A., Fujii I., Sankawa U., Mayorga M. E., Timberlake W. E., Ebizuka Y., Tetrahedron Lett., 40, 91-94 (1999).

12) Watanabe A., Fujii I., Tsai H.-F., Chang Y. C., Kwon-Chung K. J., Ebizuka Y., FEMS Microbiol. Lett., 192, 39-44 (2000).

13) Fujii I., Mori Y., Watanabe A., Kubo Y., Tsuji G., Ebizuka Y., Biosci. Biotechnol. Biochem., 63, 1445-1452 (1999).
14) Wheeler M. H., Abramczyk D., Puckhaber L. S., Naruse M., Ebizuka Y., Fujii I., Szaniszlo P. J., Eukaryot. Cell, 7, 1699-1711 (2008).

15) Kennedy J., Auclair K., Kendrew S. G., Park C., Vederas J. C. Hutchinson C. R., Science, 284, 1368-1372 (1999).

16) Feng G. H., Leonard T. J., J. Bacteriol., 177, 6246-6254 (1995).

17) Siebert P. D., Chenchik A., Kellogg D. E., Lukyanov K. A., Lukyanov S. A., Nucleic Acids Res., 23, 1087-1088 (1995).

18) Fujii I., Watanabe A., Sankawa U., Ebizuka Y., Chem. Biol., 8, 189-197 (2001).

19) Fujii T., Yamaoka H., Gomi K., Kitamoto K., Kumagai C., Biosci. Biotechnol. Biochem., 59, 1869-1874 (1995).

20) Gomi K., Iimura Y., Hara S., Agric. Biol. Chem., 51, 2549-2555 (1987).

21) Kitamoto K., Adv. Appl. Microbiol., 51, 129-153 (2002).

22) Watanabe A., Ebizuka Y., Tetrahedron Lett., 43, 843-846 (2002).

23) Hunek S., Culberson C. F., Culberson W. L., Elix J. A., Phytochemistry, 30, 706-707 (1991).

24) The pnk2 gene sequence was deposited in the DDBJ/EMBL/ GenBank under the accession number LC125898.

25) Chen Z.-G., Fujii I., Ebizuka Y., Sankawa U., Phytochemistry, 38, 299-305 (1995)

26) Fujii I., Mori Y., Watanabe A., Kubo Y., Tsuji G., Ebizuka Y., Biochemistry, 39, 8853-8858 (2000)

27) Huang K., Iwakami N., Fujii I., Ebizuka Y., Sankawa U., Curr. Genet., 28, 580-584 (1995). 